\title{
Nutritional status survey of pre school children (3-5 years) of low income families in Wattala PHI area.
}

By

K.P.Leena Chandani Karunarathna

M.Sc.

2006

The Thesis is submitted in Partial fulfillment of the M.Sc. degree in food science and technology at University of Sri Jaya wardenepura in Gangodawila, Nugegoda On2006. 


\section{DECLARATION}

The work in this was carried out by me at the university of Sri Jayawardenepura under the supervision of Dr. K.K.D.S.Ranaweera and report on this has not been submitted any other University with respect to another degree.

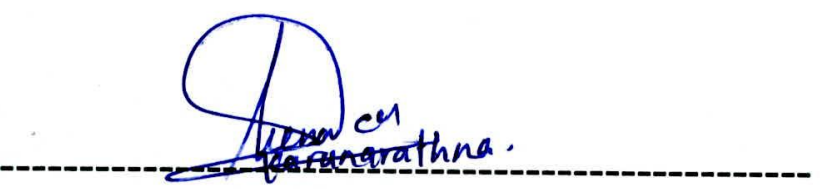

(K.P Leena chandani Karunarathna) 
I hereby certify that the statement in the preceding page made by the candidate is true and that this thesis is suitable for submission for the university for the purpose of evaluation

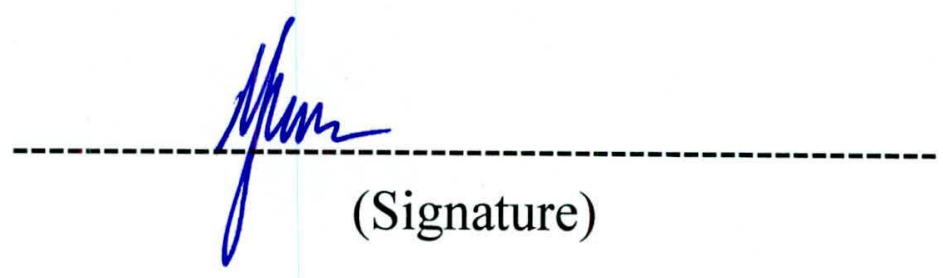

Dr. K.K.D.S.Ranaweera

Coordinator

Food science and Technology Programs

Dept. of Chemistry

University Of Sri Jayewardenepura

Sri Lanka 
TO

My Loving Mother and Father 


\section{TABLE OF CONTENTS}

Table of Contents.

List of Tables i

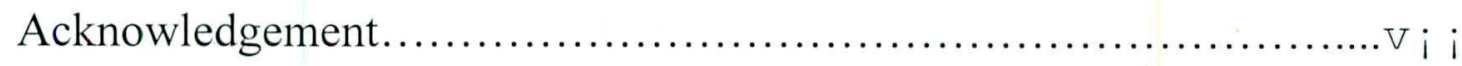

Abstract....................................................

\section{Chapter 1}

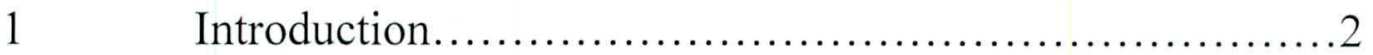

$1.1 \quad$ Background to the Study .............................. 4

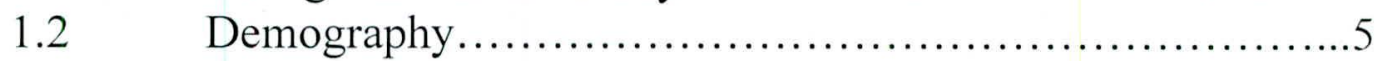

1.3 Reasons for the selection of this area......................

1.4 Objective of the survey.................................

\section{Chapter 2}

2 Literature survey of the Nutrition $\ldots \ldots \ldots \ldots \ldots \ldots \ldots$

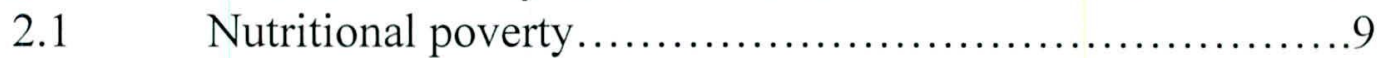

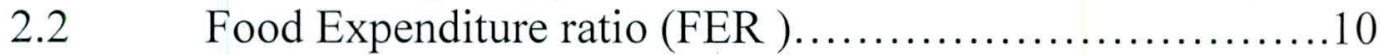

2.3 Dietary energy gap.................................... 10

2.4 Pre school - children.................................... 12

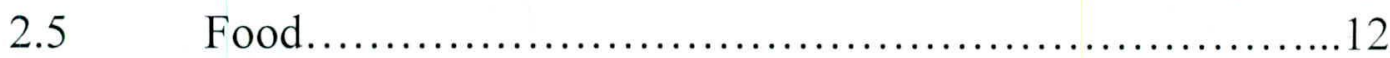

2.6 Energy production..................................... 13

$2.7 \quad$ Body Building Material.................................

2.8 Protection, Control and Regulation.........................13

$2.9 \quad$ Carbohydrates......................................... 14

2.9.1 Recommended Dietary Intake.......................... 14

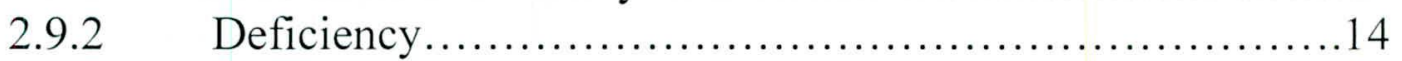

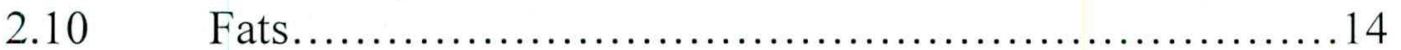

2.10.1 Recommend Dietary Intake........................... 14

2.10 .2 Deficiency.............................................

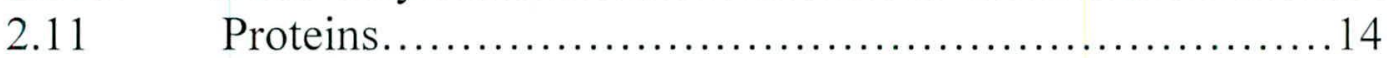

2.11.1 Recommend Dietary Intake............................14

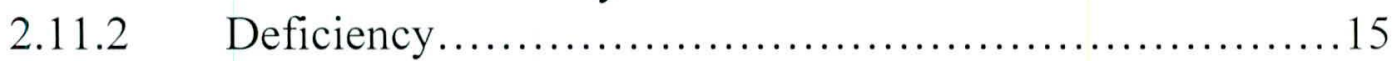

2.11.2.1 Kwashiorkor........................................... 15

2.11.2.2 Marasmus................................................. 15

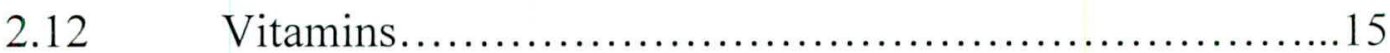

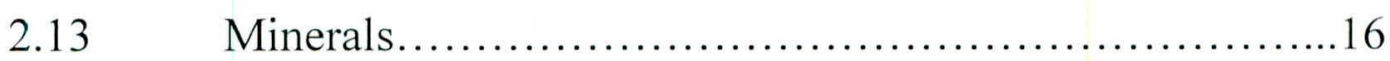

$2.14 \quad$ Water................................................... 


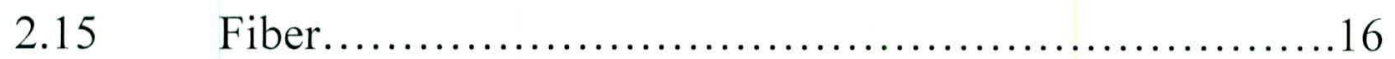

2.15.1 Deficiency............................................ 17

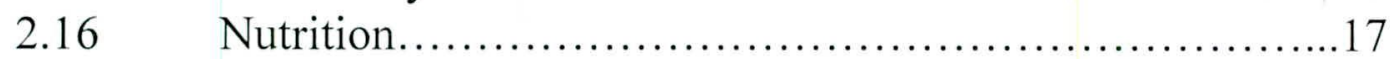

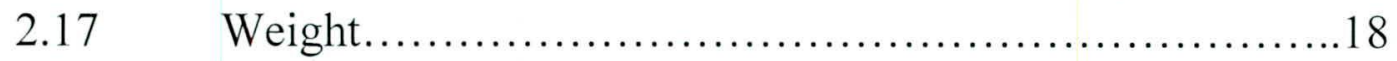

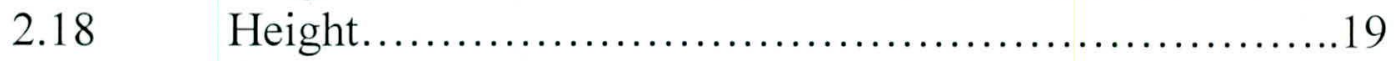

2.19 Disease.............................................. 20

2.19.1 Nutritional Disease...................................20

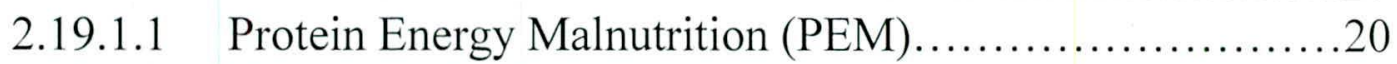

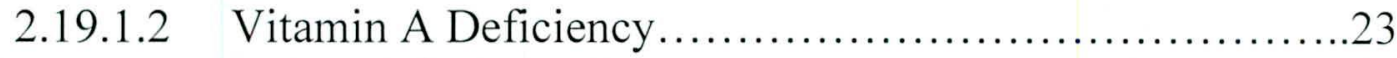

2.19.1.3 Iodine deficiency disorder.............................24

2.19.1.4 Nutritional Anemia.....................................24

2.19.2 Infectious Disease..................................... 25

2.19.2.1 How Infections interfere with child nutrition...............25

2.19.3 Common illness affecting nutritional status of children....27

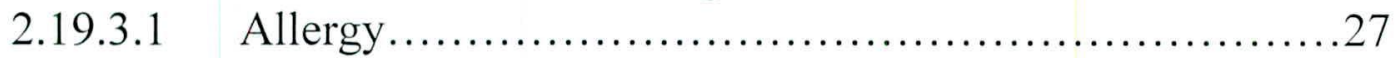

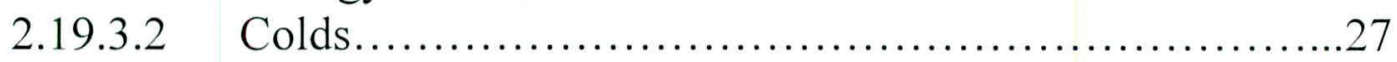

2.19.3.3 Constipation........................................... 27

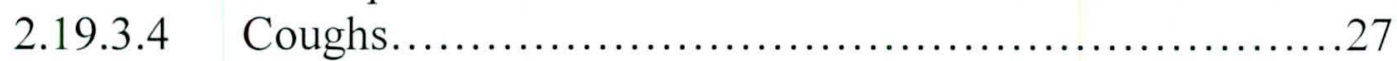

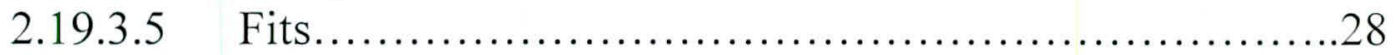

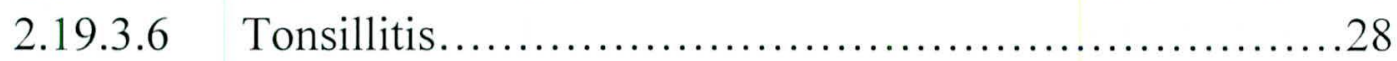

2.19.3.7 Diarrhoea...............................................

2.19.3.8 Measles..............................................

2.19.3.9 Worm infectious.................................... 29

\section{Chapter 3}

3

3.1

3.2

3.3

3.4

3.5

3.6

3.7

3.8

3.9

3.10

3.11

3.12

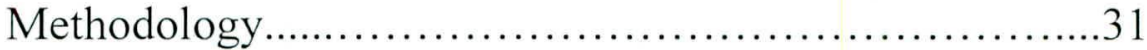

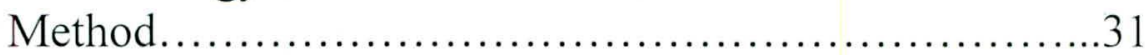

Primary data collection.................................31

Selection of Data...................................... 31

Selection of Population..................................31

Interview Schedule Method..............................32

Weight.............................................. 32

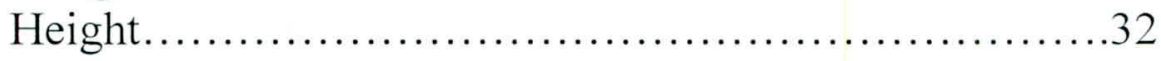

Dietary Survey......................................... 32

Pre survey visit......................................33

Time duration of data collection.........................33

Unstructured Interview.................................... 33

Field Observation........................................33 
3.13 Variable..............................................

3.14 Calculating Methodology ............................34

\section{Chapter 4}

4

4.1

4.1.1

4.1.2

4.1 .3

4.1.4

4.1.5

4.1.6

4.1.6.1

4.1.6.2

4.1 .7

4.1.7.1

4.1.7.2

4.1 .8

4.1.9

4.1.9.1

4.1.9.2

4.1 .10

4.1 .11

4.1.11.1

4.1.12

4.1.12.1

4.1.12.2

4.1.12.3

4.1 .13

4.1 .14

4.1 .15

4.1 .16

4.1.16.1

4.1.17

4.1 .18

4.1 .19

4.1.19.1

Results. 36

Socio - Economic Survey ............................. 36

Age distribution....................................... 36

Sex Distribution...................................... 36

Nationality Distribution................................. 36

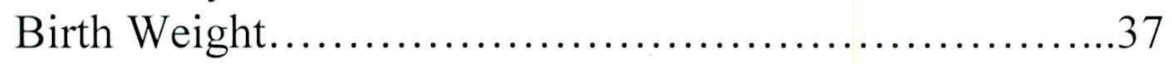

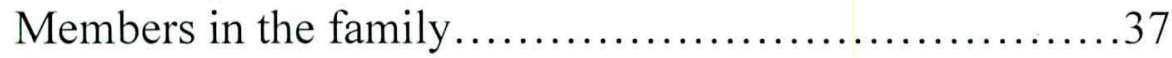

Educational Level........................................ 37

Mother's Educational Level......................... 37

Father's Educational Level................................ 38

Weight and Height according to the age ..................38

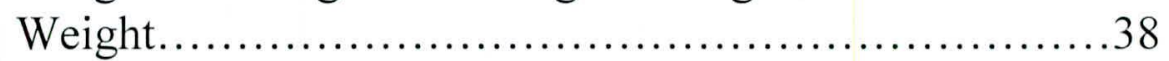

Height............................................... 38

Immunization ......................................... 38

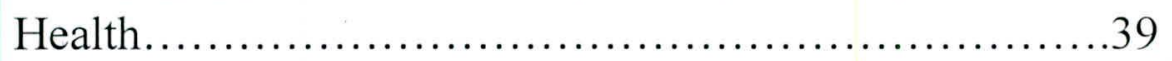

Types of diseases......................................... 39

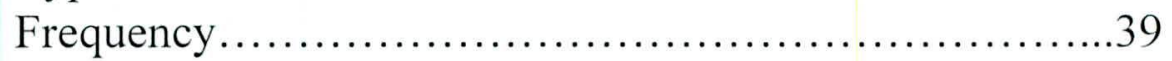

Treatment............................................ 39

Media................................................ 40

Frequency of using Mass Media.........................40 40

Physical Mental Activities of the child....................40

Physical Activity...................................... 40

Mental Activity.......................................40

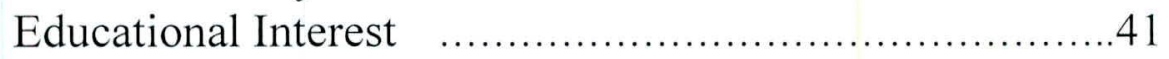

Family Planning ..................................... 41

Mothers knowledge about Diet's Malnutrition............41

Traditional believes on child's feeding...................41

Malnutrition Problem.................................4 42

Way they knew...................................... 42

Breast feeding....................................... 42

Nature of child's eating................................42

Supplementary food..................................43

Supplementary food..................................43 
4.1.19.2 Types of supplementary food..........................43

4.1.19.3 Frequency of in taking supplementary food per day.....43

4.1.19.4 Frequency of in taking supplementary food per week....44

4.1.20 Feeding Equipment..................................44

4.1.20.1 Methods of cleaning................................44

4.1.21 Food preparation...................................44

4.1.22 Source of drinking water.............................44

4.1.23 Nature of the water given for the children................45

4.1.24 Housing Environment...............................45

4.1.24.1 Ownership of the house............................. 45

4.1.24.2 Status of the house................................... 45

4.1.24.3 No of rooms in the house............................ 45

4.1.24.4 Ventilation and Spare for the children..................46

4.1.25 Sanitation...........................................46

4.1.25.1 Toilet Facilities......................................46

4.1.25.2 Method of removing fecal of the child..................46

4.1.25.3 Method of garbage removal.........................46

4.1.26 Employment of mother..............................46

4.1.26.1 Who care the children.............................47

4.1.27 Home garden and Animal Husbandry..................47

4.1.28 Monthly income..................................47

4.2 Nutritional Status Survey ..........................48

$4.3 \quad$ Statistical Analysis................................5

4.3.1 Nutritional Status with Birth Weight..................59

4.3.2 Nutritional Status with No. of Members in the Family..60

4.3.3 Nutritional Status with Monthly Income.................61

4.3.4 Nutritional Status with Mother's Educational level......62

\section{Chapter 5}

References...................................................... 65

Appendix 1 - Questionnaire and Dietary Survey........................67

Appendix 2 - Collected Data........................................... 77 


\section{LIST OF TABLES}

Table 2.1 Percentage households receiving less than minimum .9 Requirements ( $<100 \%$ req ) less than $80 \%$ requirements $(<80 \%$ req) Nutritionally At- risk and ultra poor by household income groups Sri Lanka

Table 2.2

FER for $1960-1987$. 10

Table 2.3

Food and nutrition board, national academy of sciences. ... 11

- National research council recommended daily dietary allowances, Revised 1963 ( 4 )

Table 2.4

Standard weight for Age.( WHO reference )

Table 2.5

Standard weight for Age.( WHO reference ) 21

Table 2.6

Moderate and severe malnutrition 1987 22

Table 2.7

Protein Energy Malnutrition by province. .23

Table 2.8

Vitamin A deficiency... .23

Table 2.9

Anemia by demographic sector..... .24

Table 2.10

Infectious diseases of childhood. .. 26

Table 3.1

Variable .34

Table 4.1

Age distribution. .36

Table 4.2

Sex distribution. .36

Table 4.3

Nationality distribution. 36

Table 4.4

Birth Weight. .37

Table 4.5

Members in the family. .37

Table 4.6

Mother's Educational Level....................................37

Table 4.7

Father's Educational Level..................................38

Table 4.8

Weight 38

Table 4.9

Height. .38

Table 4.10

Immunization. .38

Table 4.11

Types of diseases Weight. .39

Table 4.12

Frequency. 39

Table 4.13

Place where get the treatment. .39

Table 4.14 Media. .40

Table 4.15

Frequency of using the media. .40 
Table $4.16 \quad$ Physical Activity...................................... 40

Table $4.17 \quad$ Mental Activity .......................................40

Table 4.18 Educational interest...................................... 41

Table $4.19 \quad$ Family Planning....................................... 41

Table 4.20 Mothers knowledge about Diet's Malnutrition..................41

Table $4.21 \quad$ Malnutrition Problem.................................... 42

Table 4.22 Way they knew the Malnutrition Problem.....................42

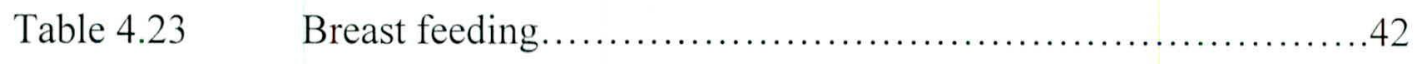

Table $4.24 \quad$ Nature of child's eating.................................42

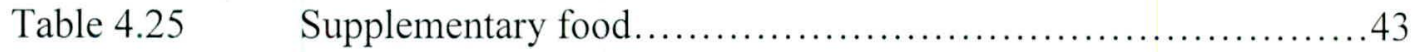

Table $4.26 \quad$ Types of the Supplementary food..........................43

Table $4.27 \quad$ Frequency of intake Supplementary food per day................43

Table 4.28 Frequency of intake Supplementary food per week..............44

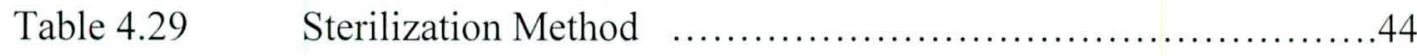

Table $4.30 \quad$ Place of Food preparation.................................. 44

Table $4.31 \quad$ Source of drinking water................................ 44

Table 4.32 Nature of the water given for the children......................45

Table $4.33 \quad$ Ownership of the house..................................45

Table $4.34 \quad$ Status of the house....................................... 45

Table $4.35 \quad$ Number of rooms in the house............................... 45

Table $4.36 \quad$ Ventilation and Spare for the children.........................46

Table $4.37 \quad$ Toilet Facilities........................................ 46

Table $4.38 \quad$ Method of removing fecal of the child.......................46

Table 4.39 Method of garbage removal................................46

Table $4.40 \quad$ Employment of mother..................................46

Table $4.41 \quad$ Taking care of the children ................................. 47

Table $4.42 \quad$ Home garden and Animal Husbandry........................47

Table $4.43 \quad$ Monthly income of the Family............................. 47

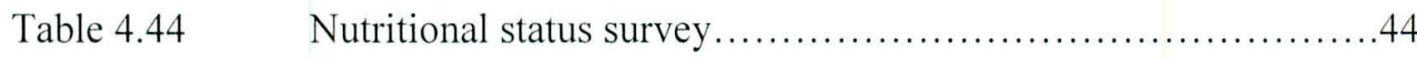




\section{ACKNOWLEDGEMENTS}

It is a pleasure for me to express my sincere thanks and gratitude to my internal supervisor Dr. K.K.D.S.Ranawera Coordinator of food and science technology of faculty of graduate studies at Sri Jayewardenepura for his continuous supervision, valuable guidance, advice and encouragement to make this study success. As well as I take this opportunity to offer my gratitude to Prof.A. Bamunuarachchi who was the former coordinator of food science and technology of faculty graduate Sri Jayewardenepura.

I wish to thank all the members of the academic staff, and Mr.Rupasinghe in non academic staff, for proving me with various opportunities and guidance to carry out the study successfully. At same time appreciate the assistance provided by $\mathrm{MOH}$ at Wattala area Dr. Swarnaloganadan, Samurdhi branch manager at wattala area, Gramasevaka in relevant area and Samurdhi officers at Wattala PHI area. They supplied me accurate information for my studies.

I offer special thanks to Ms. Nilanka Samarasinghe at university of Buttala for giving her kind support in regards of Statistical calculations.

I also would like to acknowledge the help given by the respondents who provided me valuable information for my study.

I also extremely thankful to my husband for the given support in every way, and encouragement throughout the whole work. Special word gratitude goes to my parents for their care and encouragement every time in my life. 


\section{ABSTRACT}

Usually the period under 5 year is most crucial in growth and development due to no availability of recommended nutrients. Nutritional level could be measured using direct measures such as body weight, and body height, and studying indirect measures as sanitation, infectious disease and food intake.

This survey was aimed at finding out the real nutrition status of pre school children (age 3-5 years) of low income family in Wattala PHI area, in the Colombo district.

The questionnaires were prepared in a well structured manner to collect data on the socio economic and nutritional status. This was continued for ten days. The individual nutrient intake was calculated using the standard exchange list prepared for department of nutrition.

A total of hundred and forty eight individuals were surveyed to access their nutritional status; and that was total number of 3-5 years age children live in relevant PHI areas. The socio economic status of the families was the same and the nutritional state of those children was not satisfied. All families in this PHI area were living in the *poverty level and most numbers of mothers in this PHI area were under unsatisfactory educational level, as well as and approximately $80 \%$ of mothers don't have the knowledge on balance diet and on malnutrition condition.

The results of the analysis revealed that in Wattala PHI area $82 \%$ children had faced with malnutrition problem. Further $99 \%$ children had not taken their recommended daily dietary food intake.

*Poverty: living below minimum level of income means that people are too poor to obtain basic needs, food, water, shelter, clothing, education. 
CHAPTER - 01 


\section{CHAPTER -01}

\section{Introduction}

According to the science of nutrition, our life cycle is comprised of a number of crucial periods. They are mainly the period of infancy, young children, preschooling, and lactating and pregnancy period. The period of $0-5$ year is the first vulnerable period in the life. If we are able to maintain a sound nutritional status during the infancy, it will be a good foundation for entire period of life cycle.

Under five year children again could be divided into three groups. I.e. infancy (0-1), young children (1-2), pre schooling children (3-5 years).

Nutritional needs are very high in this period since this period of years are very important in child's rapid growth and development rate; peak in the first years of life.

Daily nutritional needs of 1-3 years old child is $1300 \mathrm{Kcal}$ of energy, $25 \mathrm{~g}$ of protein, $35 \mathrm{~g}$ of fat, $13 \mathrm{~g}$ of iron and $400 \mu \mathrm{g}$ of vitamin A. ( Sri Lanka country report, Ministry of Policy Planning implementation,1991)

Nutritional needs of a child 3-5 years old is as $1600 \mathrm{Kcal}$ of energy, $28 \mathrm{~g}$ of protein, $42 \mathrm{~g}$ of fat, $14 \mathrm{~g}$ of iron and $400 \mu \mathrm{g}$ of vitamin A. ( Sri Lanka country report, Ministry of Policy Planning implementation,1991)

Malnutrition is the main problem in developing countries. According to the estimation, $1 / 3$ of the world population is malnourish. One out of every five person in the Asian region is chronically under nourished. According to survey findings of five year children, $67 \%$ in Bangladesh, $53 \%$ in India and 38\% in Pakistan and Sri Lanka undernourished ( Ash lessons and challenges poverty alleviation and food security, RAP publication, Thailand.) 
According to the WHO report of 1988/1989, it has been identified that children of 360 months showed that $36.4 \%$ of them are deficit in height for age (stunting). Further pre schooling children of $18.4 \%$ have been identified as deficit in weight for height (wasting) and 5.2\% are concurrently malnourished. According to provincial level figures in North western province $34.6 \%$ of children in 1993, 27.4\% in 1995 and 19.0 $\%$ in 1996 are malnourished (Priennin, R. 1991). Therefore such poor nutrition status of the children could be improved through well planned nutrition programs aimed at improvement of child nutrition.

Sri Lanka's economic indicators are relatively satisfactory compared with those developing countries. But on the other side of this problem is the unbalanced development of the country. Poverty is the cornerstone of malnutrition. In Sri Lanka around 2.1 million households ( $45 \%$ ) live below the poverty line. So increasing the human capital of the poor is one of the key issues to reducing poverty.

"A condition of life, so limited by malnutrition, illiteracy, disease, squalid surroundings, high infant mortality and low life expectancy as to be beneath any reasonable definition of human decency", Robert Mcnamara, President, world Bank 1978.

The capacity to earn an income is clearly a major factor in lifting families out of poverty. But in order to earn an income, an individual needs health. Strength increases the potential for income and education. Investing in the human capital of the poor is vital to ensure that they participate in the growth of the economy so that they can be productive members of society.

The other aspect is the lack of knowledge of food and nutrition due to the low educational level. 